\title{
Influência de adições minerais na elevação da temperatura de concretos massa de elevada resistência à compressão
}

\author{
Influence of mineral additions on temperature \\ increase of mass concrete of high compressive strength
}

\author{
André Valmir Saugo Ribeiro ${ }^{1,2}$, Luiz Roberto Prudêncio Jr. ${ }^{1}$, \\ Paulo Ricardo de Matos ${ }^{1,2}$ Alex Taira ${ }^{1,2}$
}

\footnotetext{
${ }^{1}$ Universidade Federal de Santa Catarina (UFSC), Departamento de Engenharia Civil, Grupo de Tecnologia em Materiais e Componentes à Base de Cimento Portland (GTec), Rua João Pio Duarte Silva, 205, CEP: 88037-000, Florianópolis, SC, Brasil.

${ }^{2}$ Universidade Federal de Santa Catarina (UFSC), Departamento de Engenharia Civil, Laboratório de Aplicações de Nanotecnologia em Construção Civil (LabNANOTEC), Rua João Pio Duarte Silva, 205, CEP: 88037-000, Florianópolis, SC, Brasil.

e-mail: andrecivilutfpr@gmail.com,prudenciouk@hotmail.com, paulorm.matos@gmail.com, alex.taira@ hotmail.com.
}

\section{RESUMO}

A construção de grandes blocos de fundação para edifícios altos tem se tornado comum no país. As altas resistências à compressão dos concretos, aliado ao fato de muitas vezes se tratar de concretos autoadensáveis, geralmente levam à elevados consumos de ligante, possivelmente originando problemas de origem térmica a estes elementos estruturais. Este estudo teve como objetivo avaliar a influência de diferentes adições minerais na elevação da temperatura de concretos massa com elevada resistência à compressão. Para isso, foi utilizado um calorímetro adiabático, o qual simula a condição de um concreto em um regime de cura autógena. As resistências à compressão dos concretos nos regimes de cura autógena e ambiente foram determinadas aos 28 dias. Complementarmente, as pastas que compõem os concretos foram avaliadas através de análise termogravimétrica aos 28 dias, a fim de verificar a influência da temperatura nas reações dos compostos das misturas. Os resultados mostraram que houve uma tendência de menor liberação de calor para os parâmetros ${ }^{\circ} \mathrm{C} / \mathrm{MPa}$ $\mathrm{e}^{\circ} \mathrm{C} / \mathrm{Kg}$ de ligante para o CP III - RS, em relação aos demais ligantes utilizados. A análise termogravimétrica indicou que o tipo de cura não influenciou significativamente na atividade pozolânica e na hidratação do cimento Portland. Por fim, verificou-se que as maiores resistências à compressão para uma mesma relação água/ligante foram obtidas pela combinação de CP V - ARI + metacaulim, pelo fato desta adição mineral apresentar elevada atividade pozolânica. Já na combinação CP V - ARI + sílica ativa, a adição mineral parece ter contribuído de forma predominante pela formação de pontos de nucleação, apresentando pouco consumo de hidróxido de cálcio.

Palavras-chave: Concreto massa; Elevação de temperatura; Adições minerais.

\section{ABSTRACT}

The construction of large foundation blocks for tall buildings has become common in the country. The high compressive strength of concretes, coupled with the fact that they are often self-compacting concretes, generally lead to high binder consumption, possibly causing problems of thermal origin to these structural elements. The objective of this study was to evaluate the influence of different mineral admixtures on the temperature rise of mass concrete with high compressive strength. For this, an adiabatic calorimeter was used, which simulates the condition of a concrete in an autogenous cure regime. The compressive strengths of the concretes in autogenous and ambient cure regimes were determined at 28 days. In addition, the pastes that composed the concretes were evaluated by thermogravimetric analysis at 28 days, in order to verify the influ- 
ence of temperature on the reactions of the compounds of the mixtures. The results showed that there was a trend of lower heat release for the parameters ${ }^{\circ} \mathrm{C} / \mathrm{MPa}$ and ${ }^{\circ} \mathrm{C} / \mathrm{kg}$ of binder for CP III-RS, compared to the other binders used. Thermogravimetric analysis indicated that the type of curing did not significantly influence the pozzolanic activity and the hydration of the Portland cement. Finally, it was verified that the higher compressive strengths for the same water/binder ratio were obtained by the combination of CP V-ARI + metacaulim, because this mineral addition showed high pozzolanic activity. On the other hand, in the CP V ARI + active silica combination, the mineral admixtures seems to have contributed predominantly to the formation of nucleation points, presenting low calcium hydroxide consumption.

Keywords: Mass concrete; Temperature rise; Mineral admixtures.

\section{INTRODUÇÃO}

A construção de edifícios cada vez mais altos é acompanhada pela necessidade de grandes blocos de fundação. Na cidade de Balneário Camboriú - SC, por exemplo, tornou-se comum a execução de blocos de fundação de milhares de $\mathrm{m}^{3}$ de concreto, chegando a $5300 \mathrm{~m}^{3}$ no edifício Infinity Coast, em 2014. Em geral, estas estruturas são executadas em concretos autoadensáveis e/ou de altas resistências, resultando em elevados consumos de ligante. Assim, tais estruturas podem apresentar elevações de temperatura excessivas, que podem ocasionar efeitos deletérios nas mesmas. Em decorrência do grande volume de concreto e ao alto consumo de cimento que é utilizado nesses blocos de fundações, é necessário um maior controle da temperatura dos concretos, uma vez que estes podem atingir altas temperaturas em seu período de cura, o que pode acarretar em diferentes patologias no concreto decorrentes deste processo [1,2]

As altas temperaturas dos grandes blocos de fundações, também chamados de concreto massa ${ }^{1}$, ocorrem em decorrência de suas grandes dimensões e aos altos consumos de cimento, pois as altas temperaturas são resultado do calor gerado na mistura, a partir da hidratação do cimento e da baixa dissipação do calor. Segundo MEHTA e MONTEIRO [3], o calor de hidratação é gerado quando ocorre a hidratação do cimento, ou seja, os compostos químicos do cimento, ao reagirem com a água para adquirirem estados estáveis de baixa energia, liberam energia dos compostos em forma de calor. Portanto, a liberação do calor pelas partículas de cimento faz com que ocorra a elevação da temperatura do concreto, o que pode acarretar em patologias de ordem térmica, tais como: Formação de Etringita Tardia e Fissuração Térmica.

Vale ressaltar que a fissuração térmica, de acordo com ALBUQUERQUE [4], é o resultado das variações volumétricas do concreto que ocorrem em função do calor gerado pela hidratação das partículas do cimento sob determinadas condições de restrição à deformação; e, segundo CARLES-GIBERGUES e HORNAIN [5], a formação da Etringita Tardia é uma reação de sulfatos que é originada internamente no concreto devido às reações de hidratação do cimento. Ressalta-se que a Etringita Tardia é consequência da elevação da temperatura a valores iguais ou superiores a $65^{\circ} \mathrm{C}$ (a partir de temperaturas entre $65^{\circ} \mathrm{C}$ e $70^{\circ} \mathrm{C}$ a etringita torna-se instável), devido a um tratamento térmico inadequado, sendo que a mesma é formada em idades tardias, após o endurecimento do concreto.

Dentre as formas de controle da temperatura do concreto, ressalta-se neste trabalho a substituição do clínquer Portland por adições minerais. Ao diminuir o consumo do clínquer Portland, ocorrerá uma menor liberação de calor nas primeiras idades e, consequentemente, o pico de temperatura desse concreto também diminuirá, podendo, assim, prevenir as patologias de ordem térmica do concreto. Ressalta-se que, a partir da necessidade da substituição parcial ao clínquer, as adições minerais mais utilizadas são os materiais pozolânicos.

Nesse seguimento, MEHTA e MONTEIRO [3] afirmaram que o calor de hidratação total produzido por reações pozolânicas é considerado a metade do calor médio produzido pela hidratação do cimento Portland. Entretanto, a utilização de materiais pozolânicos no concreto fica muitas vezes prejudicada devida à idade padronizada para a obtenção da resistência à compressão de projeto geralmente imposta pelo projetista (28 dias), não levando em consideração o ganho de resistência que uma mistura com adições pozolânicas tem entre as idades de 28 e 90 dias.

LIDUÁRIO [6] citou que a utilização de pozolanas como a sílica ativa e o metacaulim fazem com que as propriedades mecânicas do concreto sejam aprimoradas não apenas em idades avançadas, mas também em idades iniciais. Isso ocorre em função dessas duas pozolanas aumentarem os pontos de nucleação, fazendo com que o processo de hidratação seja acelerado e, também, pelo efeito fíler. Com isso, o uso da sílica ativa e do metacaulim diminui o consumo de ligante para uma mesma resistência quando comparado com o concreto produzido somente com o cimento Portland. Contudo, ressalta-se que uma das características que diferencia o metacaulim da sílica ativa é que o primeiro tem quantidade de alumina $\left(\mathrm{Al}_{2} \mathrm{O}_{3}\right)$ reativa suficiente para colabo-

\footnotetext{
${ }^{1}$ Segundo a ACI 116 (apud Mehta; Monteiro, 2014), o concreto massa é todo concreto em que o volume tem uma magnitude que necessita de meios especiais para combater uma elevada geração de calor e a decorrente variação de volume.
} 
rar com uma possível mitigação da formação de etringita tardia, enquanto o segundo não possui esse composto em sua composição.

A escória de alto forno é outra adição mineral utilizada na busca da redução da liberação de calor em concreto. Ao empregá-la em substituição ao clínquer Portland, tem-se como resultado uma diminuição da liberação de calor nas idades iniciais, seguido pela ocorrência da atividade aglomerante da escória em idades avançadas. Contudo, a escória de alto forno tem menor reatividade em comparação às adições pozolânicas supracitadas (isto é, sílica ativa e metacaulim), geralmente demandando maior consumo material ligante na mistura para uma mesma resistência aos 28 dias.

A maioria dos trabalhos que abordam a utilização de adições minerais indicam que elas causam uma diminuição no calor de hidratação do concreto, como [7 - 11]. Entretanto, isto não é uma unanimidade. No trabalho de JUNKES [12], o autor concluiu que a substituição de clínquer por cinza volante não proporcionou alteração significativa no coeficiente de elevação de temperatura adiabática, ou seja, a taxa de geração de calor do ligante composto por clínquer Portland e cinza volante foi idêntica à do cimento puro. Outro trabalho é o de COUTO, HELENE e ALMEIDA [13], onde os autores verificaram que a temperatura final do concreto produzido com CP III - RS foi alta e teve um comportamento muito semelhante ao do concreto com cimento Portland puro. Assim, demonstra-se a necessidade de mais estudos para o entendimento da elevação adiabática da temperatura de concretos contendo diferentes tipos de adições minerais em substituição ao clínquer Portland.

Com base no disposto pela literatura, verifica-se a importância da avaliação da liberação de calor pelo concreto com a substituição do clínquer por adições minerais (metacaulim, sílica ativa e escória granulada de alto forno) e, dessa forma, questiona-se: qual é a influência dos diferentes tipos de adições minerais, metacaulim, sílica ativa e escória granulada de alto forno, em substituição parcial no cimento em diferentes teores na elevação adiabática de temperatura de concretos?

\section{MATERIAIS E MÉTODOS}

\subsection{Materiais}

Os ligantes e adições minerais utilizados foram: cimentos CP V - ARI e CP III - RS, metacaulim e sílica ativa, sendo que os valores de massa específica são respectivamente $3,09 \mathrm{~kg} / \mathrm{dm}^{3} ; 2,97 \mathrm{~kg} / \mathrm{dm}^{3} ; 2,56$ $\mathrm{kg} / \mathrm{dm}^{3} ; 2,22 \mathrm{~kg} / \mathrm{dm}^{3}$. As composições químicas e características físicas dos ligantes utilizados estão apresentadas na Tabela 1 .

TABELA 1: Composição química e propriedades físicas dos cimentos CP V - ARI, CP III - RS, metacaulim (MK) e sílica ativa (SA).

\begin{tabular}{lllll}
\hline & CPV-ARI & CPIII-RS & MK & SA \\
\hline Composição química (\%) & & & & \\
\hline $\mathrm{SiO}_{2}$ & 19,19 & 24,75 & 57,0 & 85,0 \\
$\mathrm{Al}_{2} \mathrm{O}_{3}$ & 5,16 & 7,89 & 34,0 & - \\
$\mathrm{Fe}_{2} \mathrm{O}_{3}$ & 2,96 & 2,18 & - & - \\
$\mathrm{CaO}$ & 64,17 & 54,7 & - & - \\
$\mathrm{K}_{2} \mathrm{O}$ & $0,86^{*}$ & $0,61^{*}$ & - & - \\
$\mathrm{Na}$ & & & - & - \\
$\mathrm{MgO}$ & 0,76 & 2,80 & - & - \\
$\mathrm{SO}_{3}$ & 2,92 & 2,59 & - & - \\
$\mathrm{PF}$ & 3,74 & 3,55 & - & - \\
$\mathrm{RI}$ & 0,87 & 1,29 & - & - \\
$\mathrm{CaO}$ livre & 0.59 & $<1$ & - & - \\
\hline $\mathrm{Propriedades} \mathrm{físicas}$ & & & & \\
\hline $\mathrm{Massa}$ específica (g/cm & & & \\
$\mathrm{Blaine}\left(\mathrm{m}^{2} / \mathrm{kg}\right)$ & 3,10 & 3,03 & 2,56 & 2,22 \\
$\mathrm{~B} . \mathrm{E} . \mathrm{T}$. (m²/g) & 473,1 & 420,3 & - & - \\
D50 & - & - & 23.000 & 19.000 \\
Resistência à compressão 28 dias (MPa) & 15,4 & - & 1,5 & 2,0 \\
\hline
\end{tabular}

* $\mathrm{Na}_{2} \mathrm{O}$ equivalente: $\mathrm{Na}_{2} \mathrm{O}+0.64 \mathrm{~K}_{2} \mathrm{O}$; PF: perda ao fogo; $\mathrm{RI}$ : resíduo insolúvel.

Os agregados utilizados no presente estudo foram areia fina, areia de britagem, brita 0 e brita 1 . Os agregados graúdos utilizados foram agregados de origem granítica e areia de britagem de origem calcária. 
Optou-se em se fazer uma mistura de areia de britagem e natural na proporção de 60 e 40. A massa específica destes agregados, para a produção das argamassas e concretos, tiveram os seguintes valores: Areia natural fina: $2,65 \mathrm{~g} / \mathrm{cm}^{3}$, Areia de britagem: $2,80 \mathrm{~g} / \mathrm{cm}^{3}$, brita $0: 2,62 \mathrm{~g} / \mathrm{cm}^{3}$ e brita $1: 2,63 \mathrm{~g} / \mathrm{cm}^{3}$. Os resultados dos ensaios de granulometria para as britas e as areias encontram-se na Figura 1.

Como agregados miúdos, foram utilizadas uma areia natural fina de massa específica 2,65 $\mathrm{g} / \mathrm{cm}^{3} \mathrm{e}$ uma areia de britagem calcária de massa específica $2,80 \mathrm{~g} / \mathrm{cm}^{3}$. As mesmas foram empregadas na proporção de $60 \%$ areia de britagem $+40 \%$ areia natural, por ser a combinação que resulta na melhor trabalhabilidade dos concretos, conforme previamente testado. Foram empregados agregados graúdos de origem granítica de duas frações granulométricas, comercialmente conhecidos como brita 0 e brita 1 , com massas específicas respectivamente de 2,62 e 2,63 $\mathrm{g} / \mathrm{cm}^{3}$. A distribuição granulométrica dos agregados está apresentada na

Figura 1.

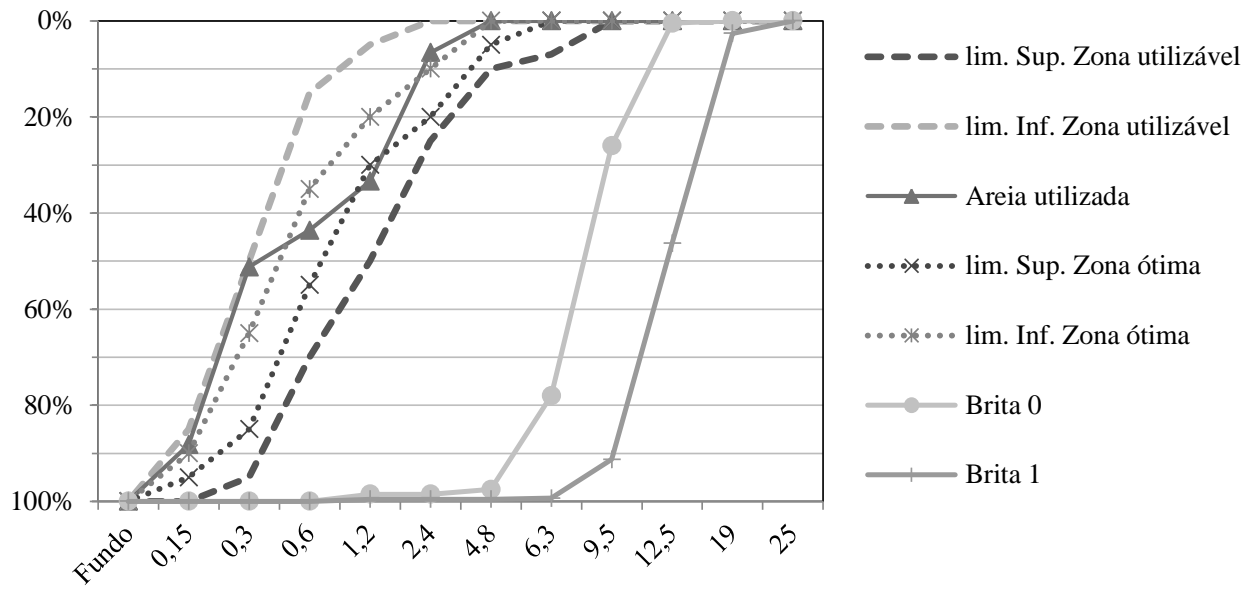

Figura 1: Distribuição granulométrica dos agregados utilizados

\subsection{Proporcionamento das misturas}

Inicialmente, foram realizados testes em argamassas com diferentes teores de substituição do cimento CP VARI por metacaulim e sílica ativa, a fim de determinar o teor ótimo de cada adição mineral. As substituições foram realizadas em volume (a fim de manter o mesmo volume de material ligante para todas as misturas), sendo testados os teores de 8, 10, 12 e 14\% para ambas as adições minerais. Foram adotados os teores que resultaram na melhor relação custo/benefício aos 28 dias para cada argamassa, isto é, menor índice R $\$ / \mathrm{MPa}$. Ainda, a escória de alto-forno foi empregada compondo o CP III - RS, no teor de $45 \pm 5 \%$.

$\mathrm{Na}$ sequência, confeccionou-se concretos com quatro classes de resistência à compressão aos 28 dias (40, 45, 50 e $55 \mathrm{MPa}$ ), para cada uma das composições de ligante (CP V-ARI, CP III-RS, CP V-ARI + sílica ativa e CP V-ARI + metacaulim). Assim, para cada combinação de ligante, foram realizadas curvas de dosagem em argamassa, com três relações água/ligante distintas. Com base nos resultados das curvas de dosagem, obteve-se o proporcionamento das misturas através dos seguintes passos: 1) Fixou-se o volume de água por $\mathrm{m}^{3}$ de concreto em 180 litros; 2) $\mathrm{O}$ consumo de ligante por $\mathrm{m}^{3}$ de concreto foi determinado multiplicando o consumo de água (180 litros $/ \mathrm{m}^{3}$ ) pelas respectivas relações água/ligante determinadas pelas curvas de dosagem; 3) A quantidade total de agregado por $\mathrm{m}^{3}$ de concreto foi definida fixando-se uma relação água/materiais secos igual a $8 \%$ em massa, sendo este último correspondente à soma do cimento e agregados; 4) As quantidades de areia e brita foram definidas para cada mistura de tal forma a obter um teor de argamassa de $52 \%$ em massa, para todas as misturas. A composição detalhada dos concretos investigados é apresentada na Tabela 2 do item 3.1.

Para a análise termogravimétrica, foram preparadas pastas com as mesmas relações água/ligante e teores de adições minerais dos concretos. As pastas foram curadas nos mesmos regimes de cura dos concretos.

\subsection{Preparação das amostras}

Os concretos foram preparados em um misturador de eixo horizontal, com capacidade nominal de 120 litros. Para cada mistura, foram preparados 20 litros, adotando-se a seguinte sequência de mistura: adição do agre- 
gado graúdo, cimento e $80 \%$ da água, e mistura por 2 min; adição do agregado miúdo e $20 \%$ da água, e misturado por $2 \mathrm{~min}$; adição do aditivo polifuncional, e misturado por $5 \mathrm{~min}$. A consistência dos concretos foi verificada pelo ensaio de abatimento de tronco de cone ABNT NBR NM 67 [14]. Após a preparação dos concretos, foram moldados seis corpos de prova cilíndricos (100 $\mathrm{mm}$ de diâmetro e $200 \mathrm{~mm}$ de altura) para cada mistura, para a determinação da resistência à compressão dos concretos. As pastas foram preparadas em um misturador de eixo vertical de $750 \mathrm{rpm}$. Inicialmente, os materiais secos (cimento + adições minerais) e a água foram adicionados ao recipiente, na sequência misturando a amostra por 2 minutos à 750 rpm. Após a mistura, as pastas foram armazenadas em recipientes selados e submetidas aos respectivos regimes de cura até a idade de ensaio.

\subsection{Regimes de cura}

Após a preparação dos concretos, os corpos de prova foram submetidos a dois regimes de cura distintos. Dos seis corpos de prova moldados para cada mistura, três foram curados em câmara úmida com temperatura e umidade constantes $\left(23^{\circ} \mathrm{C}\right.$ e $\left.95 \%\right)$, até a idade de ensaio. Os outros três foram desmoldados após 72 horas e curados em um regime de cura autógena, em um calorímetro adiabático desenvolvido por JUNCKES [12]. Este regime simula a condição de cura de uma grande massa de concreto, na qual a grande inércia térmica do material impede grandes trocas de calor com o meio. Dessa forma, o material é submetido à elevação de temperatura proveniente do calor liberado pela hidratação do cimento. Após a estabilização da temperatura, os concretos foram resfriados lentamente $\left(1,5^{\circ} \mathrm{C} / \mathrm{dia}\right)$ até $23^{\circ} \mathrm{C}$ e mantidos nesta condição até a idade de ensaio.

O calorímetro adiabático foi desenvolvido por JUNCKES [12], o qual se baseou em um modelo proposto por GAMBALE et al. [15]. O equipamento é composto por um tanque metálico preenchido com água e um sistema de monitoramento de temperatura e aquecimento de água automatizado, ilustrado esquematicamente na Figura 2. Uma amostra de 4 litros de concreto é adicionada à um recipiente metálico e emergida no tanque. O sistema monitora continuamente a temperatura da amostra, mantendo a temperatura da água que a circunda igual à da mesma, evitando assim perdas de calor da amostra de concreto. O tanque é equipado com quatro resistências de 5200 watts cada. A precisão do sistema é de $1,0^{\circ} \mathrm{C}$. Os dados de temperatura dos concretos foram registrados por meio de um aquisitor Datalogger Agilent 34970A, equipado com termopares tipo K. As temperaturas foram registradas em intervalos de 15 minutos durante 72 horas. Posteriormente ao regime de cura autógena, os corpos de prova foram resfriados à taxa de $1,5^{\circ} \mathrm{C} /$ dia.

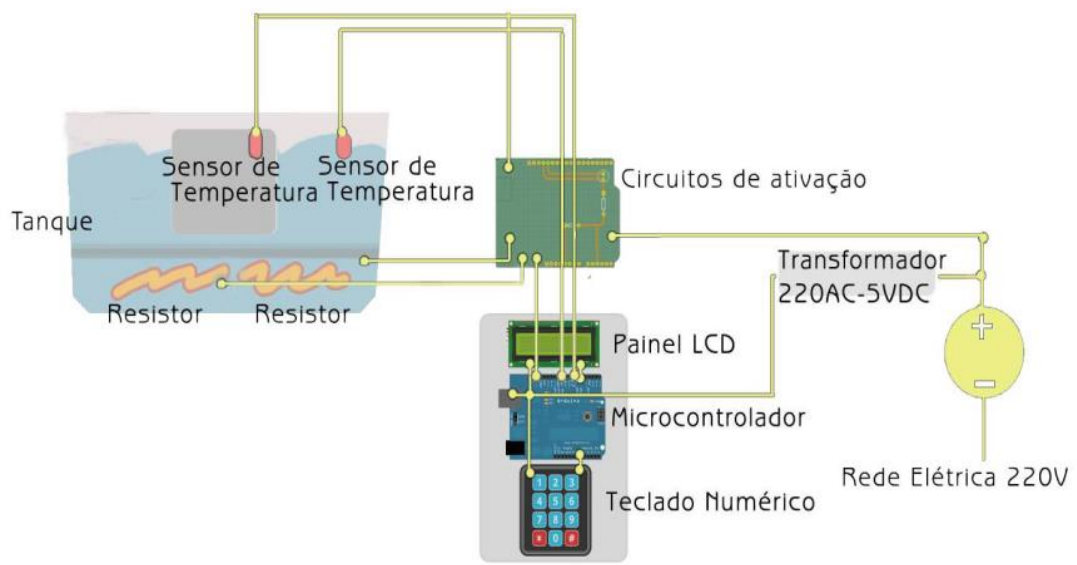

Figura 2: Esquema de funcionamento do calorímetro [12].

\subsection{Ensaios}

A determinação da resistência à compressão permitiu avaliar a influência da temperatura e do tipo e teor de adição mineral no desempenho mecânico dos concretos. o ensaio foi realizado de acordo com a NBR 5739/2018 [16], por meio de corpos de prova cilíndricos de $100 \mathrm{~mm}$ de diâmetro e $200 \mathrm{~mm}$ de altura, moldados conforme a NBR 5738/2003 [17].

O ensaio de termogravimetria foi realizado para a determinação da influência da temperatura de cura na velocidade das reações pozolânicas. Aos 28 dias, as pastas foram moídas em um moinho vibratório (Micro Pulverisette 0, FRITSCH) por 40 minutos e coletada a porção $<75 \mu \mathrm{m}$. Os testes foram feitos em um anali- 
sador SDT Q600 (TA Instruments), com taxa de aquecimento de $10^{\circ} \mathrm{C} / \mathrm{min}$ até $950{ }^{\circ} \mathrm{C}$ e vazão de $100 \mathrm{ml} / \mathrm{min}$ de $\mathrm{N}_{2}$.

\section{RESULTADOS E DISCUSSÕES}

\subsection{Resultados em argamassa}

Os estudos em argamassa apontaram que os melhores teores de adições minerais foram de $8 \%$ para a sílica ativa e $12 \%$ para o metacaulim. O teor de substituição para a sílica ativa foi determinado pela melhor relação custo/resistência. Já a escolha do teor metacaulim teve como base o trabalho de Ramlochan, Thomas e Hooton [18], os quais avaliaram a mitigação da formação de etringita tardia pelo uso de adições minerais reativas. Segundo os autores, o emprego de $8 \%$ de metacaulim em relação à massa do cimento seria suficiente para mitigar tal formação, uma vez que a alumina desta adição reagiria com o sulfato proveniente da decomposição da etringita em altas temperaturas e evitaria expansões deletérias posteriores. Entretanto, o teor de alumina reativa do metacaulim empregado por tais autores é significativamente maior do que o do metacaulim utilizado neste trabalho. Dessa forma, o teor de substituição foi corrigido para manter a mesma quantidade de alumina proposta pelos autores, resultando em uma substituição de 12\%. Os resultados de resistência à compressão para esses teores de substituição de metacaulim e sílica ativa, juntamente com os resultados dos ligantes CP V - ARI (REF) e CP III - RS (ESC), são mostrados na Figura 3.

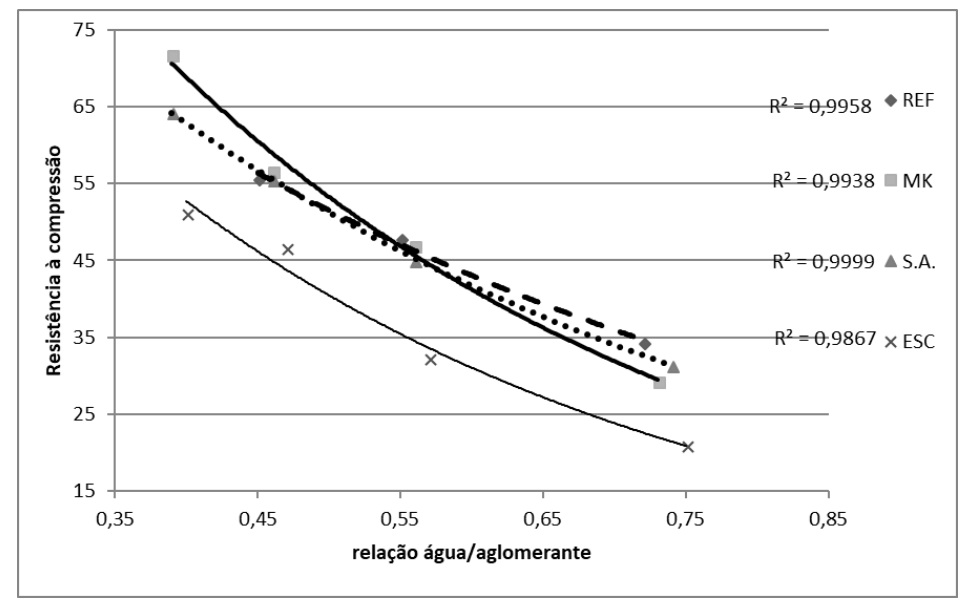

Figura 3: Curva de resistência à compressão aos 28 dias (em MPa), em função da relação água/ligante das argamassas

A partir das curvas de dosagem, foram obtidas as equações para calcular as relações água/ligante correspondente às resistências à compressão desejadas. As equações das curvas para os ligantes (1) CP V - ARI, (2) CP V - ARI + metacaulim, (3) CP V - ARI + sílica ativa e (4) CP III - RS, estão mostradas a seguir.

$$
\begin{gathered}
Y=125,75 e^{-1,79 x} \\
Y=194,29 e^{-2,58 x} \\
Y=142,73 e^{-2,049 x} \\
Y=149,77 e^{-2,627 x}
\end{gathered}
$$

Dessa forma, foi possível determinar o proporcionamento das misturas para cada classe de resistência e

\begin{tabular}{|c|c|c|c|c|c|c|c|c|}
\hline \multicolumn{9}{|c|}{ QUANTITATIVO DE MATERIAIS PARA PRODUÇÃO DE $1 \mathrm{M}^{3}{ }^{3}$ DE CONCRETO } \\
\hline FC28 & 40 MPA & & & & 45 MPA & & & \\
\hline CONSUMOS (KG/M³) & CP V - ARI & MK & S.A. & CP III - RS & CP V - ARI & MK & S.A. & CP III - RS \\
\hline
\end{tabular}
combinação de ligantes. Conforme citado no item 2.2, as quantidades de materiais para a produção de 1 metro cúbico de concreto são apresentadas na Tabela 2.

Tabela 2: Quantidade de materiais para produção de 1 metro cúbico de concreto 


\begin{tabular}{l|l|l|l|l|l|l|l|l} 
CIMENTO & 281,3 & 263,6 & 273,3 & 360 & 313,6 & 285 & 297,2 & 393,9 \\
\hline METACAULIM & 0 & 30 & 0 & 0 & 0 & 32,4 & 0 & 0 \\
\hline SÍLICA ATIVA & 0 & 0 & 17,1 & 0 & 0 & 0 & 18,6 & 0 \\
\hline AREIA NATURAL & 360,7 & 355,7 & 357,1 & 330,8 & 348,6 & 347 & 347,7 & 318,2 \\
\hline AREIA DE BRITAGEM & 541 & 533,6 & 535,6 & 496,2 & 522,9 & 520,5 & 521,5 & 477,4 \\
\hline BRITA 0 & 524,5 & 524,5 & 524,5 & 526,3 & 525,4 & 525,4 & 525,4 & 527,4 \\
\hline BRITA 1 & 524,5 & 524,5 & 524,5 & 526,3 & 525,4 & 525,4 & 525,4 & 527,4 \\
\hline ÁGUA & 180 & 180 & 180 & 180 & 180 & 180 & 180 & 180 \\
\hline FC28 & $50 \mathrm{MPA}$ & & & & $55 \mathrm{MPA}$ & & & \\
\hline CONSUMOS (KG/M $\left.{ }^{3}\right)$ & $\mathrm{CP} \mathrm{V} \mathrm{-} \mathrm{ARI}$ & $\mathrm{MK}$ & $\mathrm{S} . \mathrm{A}$. & $\mathrm{CP}$ III - RS & $\mathrm{CP}$ V - ARI & MK & S.A. & CP III - RS \\
\hline CIMENTO & 349,5 & 307,2 & 332,2 & 431,7 & 391,3 & 330,5 & 360,5 & 472,4 \\
\hline METACAULIM & 0 & 35 & 0 & 0 & 0 & 37,6 & 0 & 0 \\
\hline SÍLICA ATIVA & 0 & 0 & 20,8 & 0 & 0 & 0 & 22,5 & 0 \\
\hline AREIA NATURAL & 335 & 337,9 & 333,6 & 303,1 & 319,3 & 327,6 & 321,6 & 286,8 \\
\hline AREIA DE BRITAGEM & 502,5 & 506,9 & 500,4 & 454,7 & 478,9 & 491,4 & 482,4 & 430,2 \\
\hline BRITA 0 & 526,3 & 526,3 & 526,3 & 527,4 & 527,4 & 526,3 & 526,3 & 527,4 \\
\hline BRITA 1 & 526,3 & 526,3 & 526,3 & 527,4 & 527,4 & 526,3 & 526,3 & 527,4 \\
\hline ÁGUA & 180 & 180 & 180 & 180 & 180 & 180 & 180 & 180 \\
\hline
\end{tabular}

\subsection{Resultados dos concretos no estado fresco}

Após a preparação dos concretos, foram realizados os ensaios de consistência e massa específica das misturas, além da determinação do teor de aditivo utilizado para cada uma das misturas e os respectivos teores de ar incorporado. Todos os concretos produzidos apresentaram baixos teores de ar incorporado, de no máximo $1,91 \%$. Observou-se que nas misturas produzidas com CP III - RS, houve uma tendência de uma maior incorporação de ar, que pode ser explicado pelo alto consumo de ligante utilizado. Isso provavelmente levou a concretos com maior viscosidade, o que dificultou o adensamento dos mesmos e provavelmente resultou em maiores teores de ar nas misturas.

Com relação aos consumos de aditivo, verifica-se que, para um mesmo abatimento, houve um aumento no teor empregado com o aumento da resistência à compressão, independente do ligante utilizado. Isso provavelmente se deve ao fato de o aumento da resistência à compressão estar ligado ao aumento do consumo de ligante, uma vez que o volume de água foi fixado para todas as misturas. De fato, pode-se observar este comportamento na Figura 4, a qual ilustra os teores de aditivo para cada classe de resistência à compressão, para os diferentes ligantes empregados.

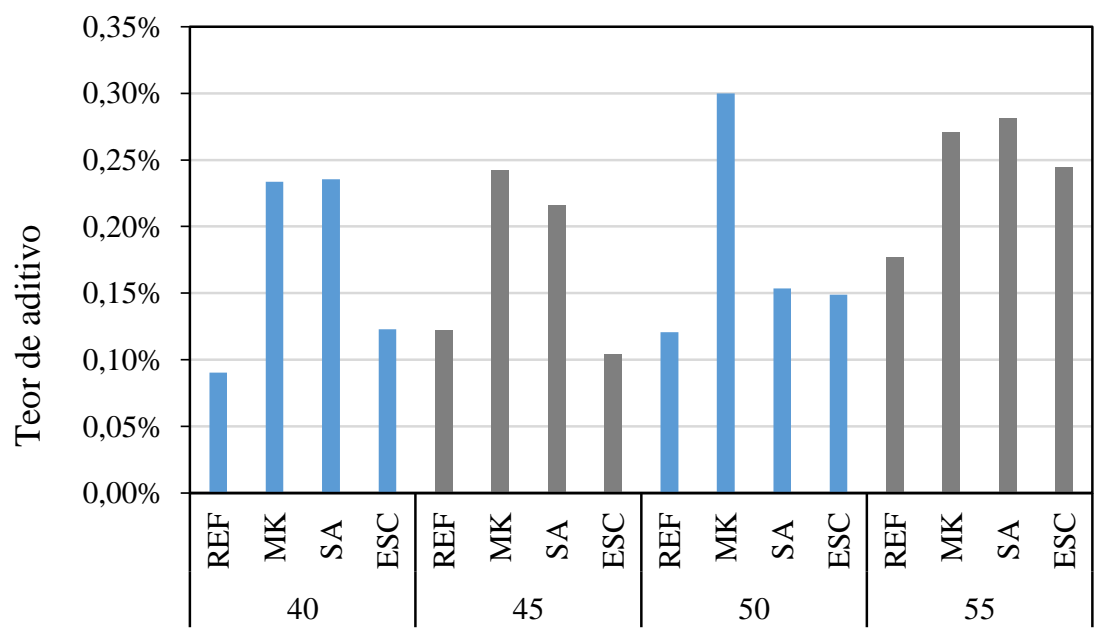


Figura 4: Teores de aditivo empregados.

Conforme ilustrado na Figura 4, os teores empregados aumentaram progressivamente de 0,17\% em média para a classe de $40 \mathrm{MPa}$, até $0,24 \%$ em média para a classe de $55 \mathrm{MPa}$. Ainda, nota-se que, no geral, as misturas contendo metacaulim (MK) e sílica ativa (SA) demandaram teores de aditivo superiores as demais, chegando a valores maiores do que $100 \%$ superior ao da referência (MK 40 e 50, e SA 50). Tal constatação pode ser explicada pela elevada superfície específica destas adições minerais, até 50 vezes superior à do cimento Portland [19]. A incorporação de partículas finas resulta na maior adsorção de água às mesmas, consequentemente resultando em uma menor quantidade de água disponível para lubrificar os grãos. Assim, para atingir a trabalhabilidade desejada, foram necessários maiores teores de aditivo para as misturas contendo tais adições.

\subsection{Resultados do ensaio de resistência à compressão dos concretos}

De modo geral, o regime de cura não exerceu influência significativa na resistência à compressão dos concretos, como ilustra a Figura 5. Isso pode ser explicado pelo fato de que a cura em temperaturas elevadas beneficia a resistência à compressão nas primeiras idades, pelo aumento da velocidade de hidratação dos compostos, principalmente na presença de adições minerais reativas, fato este constatado por diversos autores [20 - 23]. Entretanto, tal aceleração causa um prejuízo na formação da microestrutura do concreto, comprometendo a resistência do material à longo prazo [24]. Dessa forma, espera-se que, em idades iniciais, as resistências à compressão dos concretos curados em regime adiabático sejam maiores do que as resistências dos concretos curados em temperatura ambiente. Entretanto, em idades superiores, espera-se que as resistências à compressão dos curados em temperatura ambiente superem às dos concretos curados em regime adiabático.

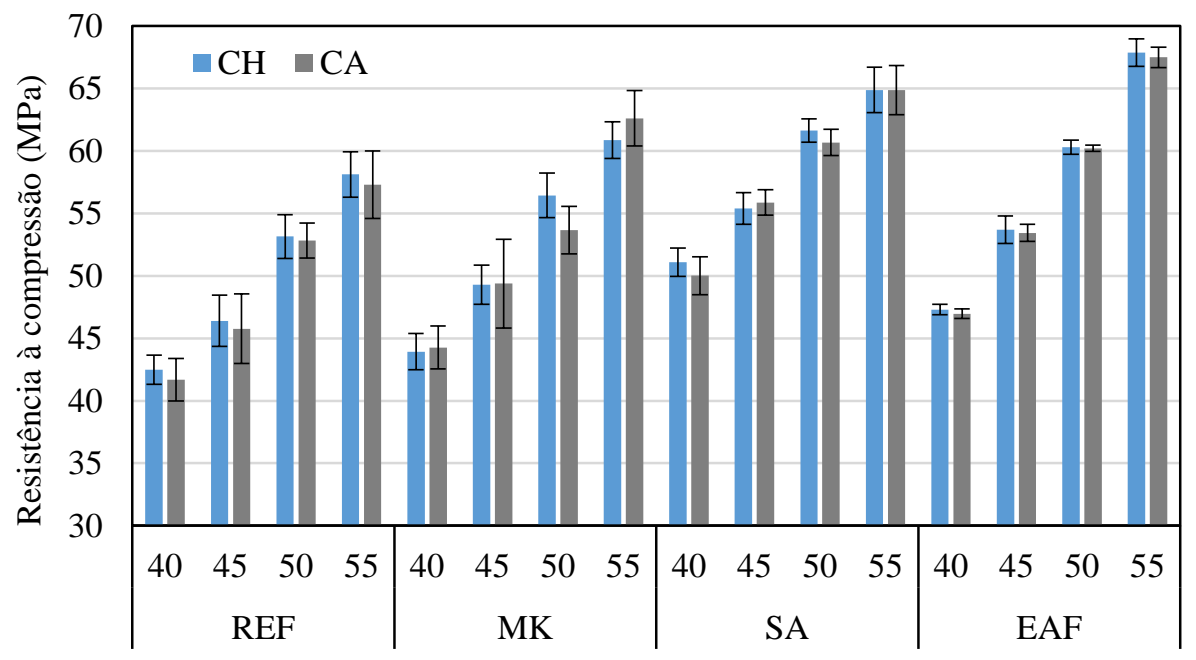

Figura 5: Resistência à compressão dos concretos aos 28 dias, para os diferentes regimes de cura.

Verificou-se ainda que o tipo de adição mineral empregado apresentou influência na resistência à compressão dos concretos. Explica-se tal fato em decorrência da alta reatividade do metacaulim e sílica ativa, e também pela elevada superfície específica e quantidade de fases reativas destes materiais [25]. Além disso, tais adições promovem um efeito de nucleação para a precipitação e formação de C-S-H, resultando na hidratação mais eficiente do cimento e consequente aumento da resistência mecânica [26, 27]. Já a escória de altoforno tem reatividade inferior aos demais ligantes empregados, sendo o ganho de resistência mecânica promovida pela mesma menos notável aos 28 dias.

Como os concretos foram dosados com diferentes relações água/ligante para cada tipo de ligante, foi construída uma curva de resultados de resistência à compressão aos 28 dias para cada tipo de ligante, essa curva pode ser observada na Figura 6. 


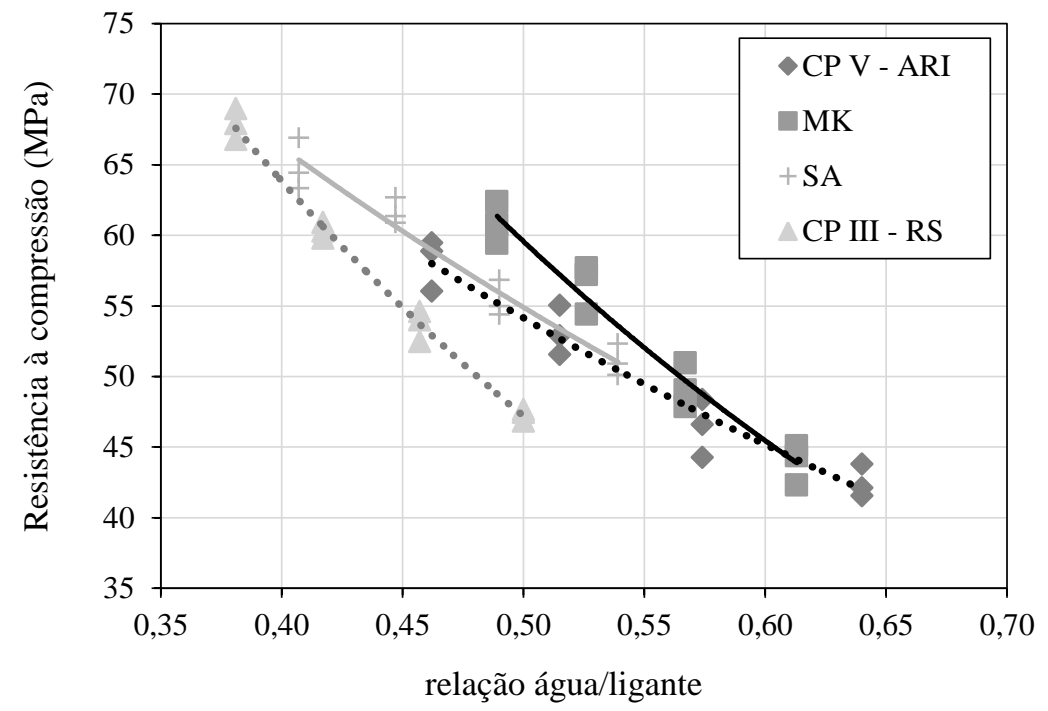

Figura 6: Curva de resistência à compressão aos 28 dias dos concretos produzidos com diferentes ligantes

A partir disso verifica-se que, houve a tendência do ligante CP V - ARI + metacaulim obter maior resistência para uma mesma relação água/ligante em relação aos demais ligantes, seguido pelo ligante $\mathrm{CP}$ V ARI + sílica ativa, CP V - ARI (REF) e por CP III - RS.

\subsection{Resultados dos ensaios de cura adiabática dos concretos}

Foram realizados ensaios de elevação da temperatura dos concretos durante os três primeiros dias de cura para cada traço, a fim de se avaliar a elevação da temperatura em cada resistência, para cada ligante. Com os resultados desses ensaios, foram estabelecidas três variáveis para uma melhor análise desses valores.

As três variáveis são: (1) ${ }^{\circ} \mathrm{C} / \mathrm{MPa}$, que representa a elevação de temperatura para cada MPa de resistência; (2) ${ }^{\circ} \mathrm{C} / 100 \mathrm{~kg}$ de ligante, representa a elevação de temperatura para cada cem quilogramas do ligante utilizado; (3) Amplitude Térmica, representa a diferença entre o menor e o maior pico de temperatura medida. Os resultados dos ensaios de elevação da temperatura no regime adiabático estão mostrados na Figura 7. 


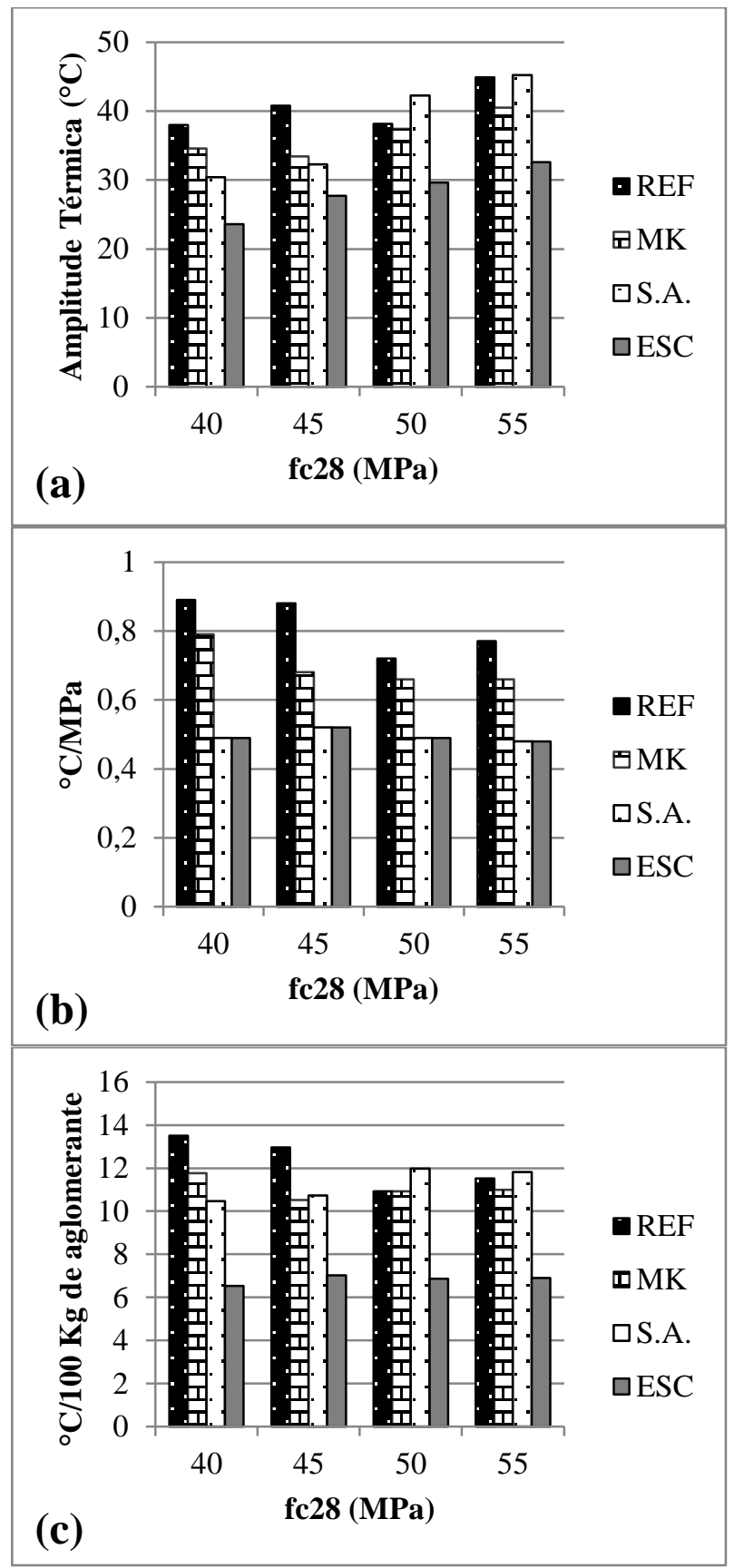

Figura 6 :Resultados para os ensaios de elevação da temperatura adiabática (a) Amplitude Térmica x resistência à compressão aos 28 dias; (b) Ganho de temperatura para cada MPa de resistência de cada concreto; (c) Ganho de temperatura para cada $100 \mathrm{Kg}$ de ligante.

Conforme ilustrado pela Figura 7, verifica-se que há uma tendência do aumento dos índices ${ }^{\circ} \mathrm{C} / \mathrm{MPa}$ e ${ }^{\circ} \mathrm{C} / 100 \mathrm{~kg}$ de ligante quando a resistência é mais baixa e quando o consumo de ligante é menor. Já a amplitude térmica tem uma tendência de ser maior quanto maior é o consumo de ligante. Ressalta-se que esses valores são válidos e compreendidos dentro das faixas de resistências, com os materiais específicos e com a mistura utilizada no presente estudo. Essas variáveis foram calculadas a partir dos resultados obtidos dos picos de temperaturas de cada mistura pela resistência à compressão aos 28 dias de cada mistura $\left({ }^{\circ} \mathrm{C} / \mathrm{MPa}\right)$ e pelo consumo de ligante de cada mistura $\left({ }^{\circ} \mathrm{C} / 100 \mathrm{~kg}\right.$ de ligante $)$.

Comparando os resultados de mesma resistência, percebe-se que houve uma tendência de diminuição das variáveis de ${ }^{\circ} \mathrm{C} / \mathrm{MPa},{ }^{\circ} \mathrm{C} / 100 \mathrm{~kg}$ de ligante e amplitude térmica, para as misturas produzidas com o ligante CP III - RS em relação aos valores da mistura de referência. Já para os ligantes CP V - ARI + sílica ativa e CP V - ARI + metacaulim, foi verificado que, para as resistências de 40 e $45 \mathrm{MPa}$, houve uma diminuição dessas variáveis. Já para as resistências de 50 e $55 \mathrm{MPa}$, existe um comportamento muito parecido em rela- 
ção à mistura produzida com CP V - ARI.

O comportamento parecido dos ligantes: CP V - ARI + sílica ativa, CP V - ARI + metacaulim e CP V - ARI pode ser explicado devido aos ligantes, sílica ativa e metacaulim, terem uma alta reatividade e por suas substituições serem baixas em relação à mistura produzida com CP III - RS, além do que, o metacaulim e a sílica ativa têm como características a criação de pontos de nucleação.

O parâmetro ${ }^{\circ} \mathrm{C} / \mathrm{MPa}$ foi verificado para que se possa calcular o aumento da temperatura de um concreto, para um tipo de ligante e para uma resistência requisitada. Este parâmetro indicou que, para todas as resistências, o ligante $\mathrm{CP} \mathrm{V} \mathrm{-} \mathrm{ARI} \mathrm{teve} \mathrm{uma} \mathrm{tendência} \mathrm{em} \mathrm{produzir} \mathrm{maior} \mathrm{quantidade} \mathrm{de} \mathrm{temperatura} \mathrm{para}$ cada MPa. Já os ligantes contendo metacaulim e sílica ativa tiveram uma liberação de temperatura por MPa alta e parecida com a do CP V - ARI nas resistências de 50 e $55 \mathrm{MPa}$. O ligante CP III - RS liberou cerca de $40 \%$ a menos de temperatura em relação ao CP V - ARI, e cerca de $30 \%$ menos do que os que continham metacaulim e sílica ativa, independente da resistência.

O Parâmetro de ${ }^{\circ} \mathrm{C} / 100 \mathrm{~kg}$ de ligante resultou em um valor maior para os concretos produzidos com sílica ativa, metacaulim e CP V - ARI. O ligante CP III - RS apresentou valor de até $45 \%$ menor em relação ao CP V - ARI e 39\% menor em relação ao metacaulim e a sílica ativa, para este parâmetro, indicando uma menor liberação de temperatura para todos os teores de ligante utilizado no presente estudo.

Outro parâmetro verificado com os dados supracitados é a amplitude térmica. Nesse sentido, pode-se verificar que o concreto produzido com CP III - RS obteve uma menor amplitude térmica, para todas as resistências com os diferentes tipos de ligantes utilizados. O ligante contendo metacaulim teve sua amplitude térmica menor do que o do ligante CP V - ARI, em todas as resistências. Já em comparação com o que continha sílica ativa, seu comportamento foi o de ter um ganho maior de temperatura nas resistências de 40 e $45 \mathrm{MPa}$ e menor ganho para as resistências de 50 e $55 \mathrm{MPa}$. O ligante contendo sílica ativa apresentou um comportamento parecido com o do CP V - ARI para as resistências maiores que $45 \mathrm{MPa}$. Já para resistências menores ou iguais, apresentou um ganho de temperatura menor.

Para análise desses dados descritos acima, foi aplicada análise estatística TWO-WAY e o teste de Duncan, visando à verificação da influência do tipo de ligante e a faixa de resistência e os ligantes que mais liberam temperatura por resistência e por $\mathrm{kg}$ de ligante.

Tabela 3: ANOVA para o parâmetro Amplitude Térmica.

\begin{tabular}{llllll}
\hline \multicolumn{7}{c}{ ANOVA } \\
\hline FONTE & $\mathrm{SQ}^{2}$ & $\mathrm{GDL}^{3}$ & $\mathrm{MQ}^{4}$ & $\mathrm{~F}^{5}$ & $\mathrm{~F} 0,05(3,9)^{6}$ \\
\hline Resistência & 194,469 & 3 & 64,823 & 8,37 & 3,86 \\
\hline Ligante & 320,506 & 3 & 106,835 & 13,79 & 3,86 \\
\hline Resíduo & 69,709 & 9 & 7,745 & - & - \\
\hline Total & 584,684 & 15 & - & - & - \\
\hline
\end{tabular}

Tabela 4: Anova para o parâmetro ${ }^{\circ} \mathrm{C} / \mathrm{MPa}$.

\begin{tabular}{llllll}
\hline \multicolumn{7}{c}{ ANOVA } \\
\hline Fonte & SQ & GDL & MQ & F & F0,05(3,9) \\
\hline Resistência & 0,0105 & 3 & 0,00351 & 1,177 & 3,86 \\
\hline Aglomerante & 0,2100 & 3 & 0,07001 & 23,488 & - \\
\hline resíduo & 0,0268 & 9 & 0,00298 & - & - \\
\hline Total & 0,2474 & 15 & - & - & - \\
\hline
\end{tabular}

\footnotetext{
${ }^{2}$ Soma dos quadrados dos resultados do parâmetro em questão.

${ }^{3}$ Grau de liberdade: Número de observações independentes menos o número de restrições lineares.

${ }^{4}$ Média quadrada do parâmetro em questão.

${ }^{5}$ Distribuição F calculada através dos resultados do experimento.

${ }^{6}$ Valor da Distribuição para a confiabilidade desejada (95\%) com os graus de liberdade.
} 
Tabela 5: Teste de Duncan para o tipo de ligante.

\begin{tabular}{llll}
\hline \multicolumn{4}{c}{ DUNCAN } \\
\hline Aglomerantes & dados & calculado & Resultado \\
\hline Ref - CP III RS & 0,32 & 0,1171585 & DFS \\
\hline Ref-S.A. & 0,1575 & 0,1051637 & DFS \\
\hline Ref-MK & 0,1175 & 0,0859163 & DFS \\
\hline MK-S.A. & 0,04 & 0,0859163 & NDFS \\
\hline MK - CP III RS & 0,2025 & 0,1051637 & DFS \\
\hline S.A. - CP III RS & 0,1625 & 0,0859163 & DFS \\
\hline
\end{tabular}

Tabela 6: ANOVA para o parâmetro ${ }^{\circ} \mathrm{C} / 100 \mathrm{Kg}$ de ligante.

\begin{tabular}{llllll}
\hline \multicolumn{7}{c}{ ANOVA } \\
\hline Fonte & SQ & GDL & MQ & F & F0,05(3,9) \\
\hline Resistência & 0,3396 & 3 & 0,11322 & 0,152 & 3,86 \\
\hline Aglomerante & 68,6936 & 3 & 22,89788 & 30,665 & - \\
\hline resíduo & 6,7203 & 9 & 0,74670 & - & - \\
\hline Total & 75,7536 & 15 & - & - & - \\
\hline
\end{tabular}

Tabela 7: Teste de Duncan para o parâmetro ${ }^{\circ} \mathrm{C} / 100 \mathrm{Kg}$ de ligante.

\begin{tabular}{llll}
\hline \multicolumn{4}{c}{ DUNCAN } \\
\hline Aglomerantes & Dados & Calculado & Resultado \\
\hline Ref - CP III RS & 5,393 & 1,611 & DFS \\
\hline Ref-S.A. & 1,173 & 1,446 & NDFS \\
\hline Ref-MK & 0,985 & 1,181 & NDFS \\
\hline K-S.A. & 0,188 & 1,181 & NDFS \\
\hline MK - CP III RS & 4,408 & 1,446 & DFS \\
\hline S.A.- CP III RS & 4,220 & 1,181 & DFS \\
\hline
\end{tabular}

Verifica-se, pela Tabela 3, com 95\% de confiabilidade, que o tipo de ligante utilizado e a resistência de dosagem na mistura têm influência no parâmetro amplitude térmica $\left(\mathrm{F}_{0,05}<\mathrm{F}\right)$, ou seja, certifica-se que a liberação de temperatura total do ligante é influenciada pela resistência de dosagem e o tipo de ligante utilizado.

Pela Tabela 4, pode-se aceitar, com 95\% de confiabilidade, que o tipo de ligante utilizado na mistura tem influência no parâmetro ganho de temperatura para cada MPa de resistência, o que não ocorre com a faixa de resistência estudada. Para a Tabela 5, com a confiabilidade de 95\%, pode-se aceitar que os resultados obtidos se diferenciaram significativamente (DFS) para quase todos os ligantes, sendo que somente os ligantes contendo metacaulim e sílica ativa não se diferenciaram significativamente. A partir da análise, aceita-se que o tipo de ligante que libera maior calor, dentre os ligantes deste estudo, é o CP V - ARI, seguido pelos que continham metacaulim e sílica ativa, que tiveram a tendência de ter o mesmo comportamento e, por último, o ligante CP III - RS, que se demonstrou diferente significativamente de todos.

Verifica-se pela Tabela 6, com 95\% de confiabilidade, que o tipo de ligante tem influência no parâmetro ${ }^{\circ} \mathrm{C} / 100 \mathrm{~kg}$ de ligante. Além disso, conclui-se que a resistência não tem influência para este mesmo parâmetro $\left(\mathrm{F}_{0,05}>\mathrm{F}\right)$. Na Tabela 7 , verifica-se, com a confiabilidade de $95 \%$ para o parâmetro ${ }^{\circ} \mathrm{C} / 100 \mathrm{~kg}$, que todos os resultados obtidos se diferenciaram significativamente (DFS) para o ligante CPIII-RS em relação aos demais. Para os demais, não foi verificada diferença significativa entre eles.

Sendo assim, comprova-se que o tipo de ligante que libera menor temperatura para cada $100 \mathrm{Kg}$ de ligante dentre os analisados, é o CPIII-RS. Isso pode ser constatado em trabalhos como o DIAS et al. [28], 
onde foram realizados ensaios de elevação de temperatura adiabática com os teores de $0 \%, 25 \%, 55 \%, 80 \%$ e $100 \%$ de escória, sendo que os autores observaram que, conforme o teor aumentava, ocorria a diminuição da temperatura adiabática. Além disso, LIDUÁRIO et al. [9] também verificou que a quantidade de calor liberado adiabaticamente pelo concreto produzido com escória foi menor até a idade de 72 horas, quando comparado com os concretos produzidos com as substituições de metacaulim, sílica ativa e a referência.

HAN et al. [11] mostraram a liberação de calor pelas pastas produzidas com cimento puro, cimento com substituição de escória (nos teores de 30\% e 70\%), e pó de quartzo (nos teores de 30\% e 70\%) que mostra a energia liberada, em forma de calor, para uma idade de 72 horas. Eles afirmam que, conforme ocorre o aumento de substituição de cimento por escória, o calor de hidratação liberado é menor. Os autores explicam isso pela maior quantidade de cimento na substituição de $30 \%$ de escória, aumentando assim o calor liberado pela hidratação das partículas. Além disso, a quantidade de $\mathrm{OH}^{-}$é maior para a substituição de $30 \%$ do que para a substituição de $70 \%$, o que estimula a reação da escória.

Os autores afirmaram que, conforme houve o aumento da quantidade de substituição de escória em relação ao cimento, ocorreu a diminuição da liberação do calor de hidratação, devido à redução do ambiente alcalino ativador da escória, que é fornecido pela hidratação do clínquer. O que também pode ser considerado é a reatividade da escória utilizada, pois quanto maior a fração vítrea de uma escória, maior será sua reatividade e, consequentemente, maior será a reação e também a liberação de calor [29]. Confirmando os resultados apresentados anteriormente, pode-se citar os trabalhos de [28 - 32].

O comportamento de menor liberação de temperatura pela escória apresentado durante os 3 dias de cura térmica neste estudo, pode ser justificado devido à reatividade dos ligantes, sendo a escória menos reativa do que os demais. A liberação do calor de hidratação das partículas de escória pode ocorrer lentamente, isso porque depende da decomposição da fase vítrea pelos íons de hidroxila liberados durante a hidratação do cimento Portland [7].

Os demais ligantes não apresentaram diferença significativa na liberação de temperatura e, assim, com 95\% de confiança, aceita-se que eles liberam a mesma quantidade de temperatura para cada $100 \mathrm{~kg}$ de ligante utilizado. Esses resultados estão em consonância com os escritos de FitzGibbon (1977) apud Neville [7], o qual cita que em consumos na faixa entre 300 e $600 \mathrm{~kg} / \mathrm{m}^{3}$, esse parâmetro deve ser igual para qualquer tipo de cimento.

Nessa perspectiva, nos estudos de KADRI e DUVAL [33] NILI e SALEHI [34], sobre a substituição de cimento por sílica ativa, houve uma tendência de aumento no calor de hidratação liberado inicialmente pela pasta de ligante devido ao fato da sílica ativa promover a criação de pontos de nucleação que fazem com que as reações de hidratação ocorram mais rapidamente. Por fim, ressalta-se que, assim como nesta pesquisa, no estudo de KADRI et al [10] também houve a semelhança no calor de hidratação liberado pelos ligantes contendo metacaulim, sílica ativa e cimento Portland comum.

\subsection{Análise termogravimétrica}

Para todas as pastas, foram observadas três transições de perda de massa na curva TGA. A primeira ocorreu na faixa de $20^{\circ} \mathrm{C}$ a $400^{\circ} \mathrm{C}$, e é atribuída à evaporação da água livre até $105^{\circ} \mathrm{C}$, adicionalmente à decomposição dos hidratos de $105^{\circ} \mathrm{C}$ a $400^{\circ} \mathrm{C}$. A segunda transição ocorreu na faixa de temperatura entre 400 até $530^{\circ} \mathrm{C}$, associada à dissociação da água do $\mathrm{Ca}(\mathrm{OH})_{2}$ (portlandita). Por fim, a terceira ocorreu na faixa de 530 a $790^{\circ} \mathrm{C}$, onde se deu a descarbonatação do $\mathrm{CaCO}_{3}$ (carbonato de cálcio) [2].

A partir dos resultados dos ensaios da análise termogravimétrica, os valores de água quimicamente combinada foram retirados das curvas TG e DTG e então calculou-se o teor de hidróxido de cálcio presente nas pastas aos 28 dias, apresentados na Figura 8 a seguir, a determinação do teor de hidróxido de cálcio presente nas amostras foi feita pela equação abaixo.

$$
\mathrm{Ca}(\mathrm{OH})_{2}=\mathrm{H}_{2} \mathrm{O} \cdot \frac{M_{\mathrm{Ca}(\mathrm{OH}) 2}}{M_{\mathrm{H} 2 \mathrm{O}}}
$$

Onde:

$\mathrm{Ca}(\mathrm{OH})_{2}$ : Teor de hidróxido de cálcio $(\%)$.

$\mathrm{H}_{2} \mathrm{O}$ : Teor de água combinada com o $\mathrm{Ca}(\mathrm{OH})_{2}$, obtida pela curva TGA $(\%)$.

$\mathrm{MCa}(\mathrm{OH})_{2}$ : Massa molecular do hidróxido de cálcio - equivalente a 74g/mol.

$\mathrm{MH}_{2} \mathrm{O}$ : Massa molecular da água - equivalente a $18 \mathrm{~g} / \mathrm{mol}$. 

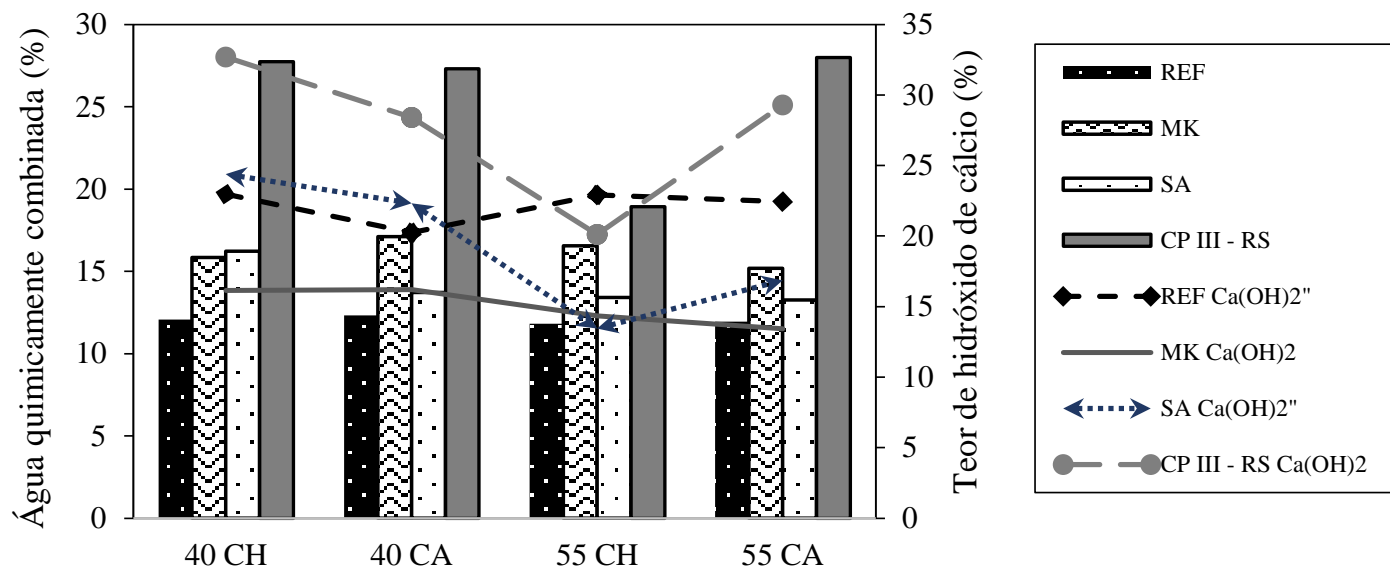

Resistência de dosagem e tipo de cura

Figura 7: Resultados obtidos através do ensaio de termogravimetria e suas correções aos 28 dias dos diferentes tipos de ligantes utilizados

Com base no ilustrado pela Figura 8, há uma tendência em se ter uma maior quantidade de água quimicamente combinada - maior o teor de hidratos - quando realizada a substituição de CP V - ARI (REF) por CP III - RS (ESC), sílica ativa ou metacaulim. Constata-se assim, que as pastas produzidas com os ligantes: sílica ativa e metacaulim apresentaram maior formação de hidratos aos 28 dias, quando comparadas com as pastas produzidas com CP V - ARI, tendo em vista que a consolidação da pasta está relacionada diretamente com o teor de hidratos formados. Ainda, houve uma tendência do aumento da quantidade de água quimicamente combinada para a resistência de $40 \mathrm{MPa}$. Segundo BERODIER e SCRIVENER [26], uma maior relação água/ligante resulta em uma maior quantidade de água disponível para hidratar o cimento, consequentemente resultando na maior formação de hidratos para uma mesma idade.

Sabe-se que a cura sob elevadas temperaturas faz com que a velocidade de hidratação do cimento acelere, acarretando uma formação de hidratos mais expressiva aos 28 dias. Esse efeito é causado devido às partículas extremamente finas presentes nos materiais, que cria pontos de nucleação e acelera o processo de hidratação das partículas [35]. Em relação ao aumento da temperatura de cura, diversos autores afirmam que conforme aumenta a temperatura de cura, acelera-se o processo de reação pozolânica [20 - 23].

Ainda, para o metacaulim e sílica ativa, foram observados menores teores de $\mathrm{Ca}(\mathrm{OH})_{2}$ nas pastas submetidas à cura autógena, e teores de hidratos ligeiramente superiores. Isso indica que a temperatura potencializou a atividade pozolânica de tais adições. Para o CP V - ARI, a maior quantidade de hidratos formados pela cura autógena indica que este regime acelerou o processo de hidratação do cimento.

Conforme ilustrado na Figura 8, o metacaulim e a sílica ativa tiveram maiores valores de água quimicamente combinada na resistência de $40 \mathrm{MPa}$ em relação à de $55 \mathrm{MPa}$. Tal constatação pode ser justificada, pois, em resistências menores, há um maior afastamento entre as partículas de cimento, ocasionada pela diminuição do consumo de ligante, o que faz com que a água consiga entrar em contato com as partículas de cimento com maior facilidade, fornecendo uma aceleração no processo de hidratação [36].

Nota-se que, independentemente do tipo de cura e da resistência, as pastas produzidas com metacaulim apresentaram maiores teores de hidratos e menores teores de hidróxido de cálcio em comparação ao CP V - ARI e CP III - RS, indicando a ação aglomerante complementar (isto é, atividade pozolânica) do metacaulim. O mesmo fator preponderante foi notado para o ligante CP III - RS, independentemente do tipo de cura e da resistência. Já para a sílica ativa, houve um aumento na quantidade de hidratos formados, porém não houve maior consumo de hidróxido de cálcio para a resistência de $40 \mathrm{MPa}$, independentemente do tipo de cura. Assim, verifica-se que houve maior influência da nucleação do que da atividade pozolânica neste caso.

\section{CONCLUSÕES}

Neste trabalho, foram avaliadas diferentes combinações de ligantes na elevação adiabática de temperatura de concretos, e a influência do regime de cura (ambiente e adiabática) na resistência à compressão dos mesmos. Os resultados do ensaio de calorimetria mostraram que o concreto contendo apenas CP V - ARI apresentou 
maiores valores de elevação de temperatura e liberação do calor por MPa de resistência à compressão em comparação aos concretos produzidos com metacaulim, sílica ativa e CP III - RS. Isso provavelmente ocorreu porque as reações das adições minerais só ocorrem em idades superiores, de forma que o calor liberado por tais reações não se sobrepôs à liberação de calor proveniente da hidratação do cimento Portland (este ocorrendo principalmente nas primeiras idades). Referente ao índice de liberação de calor por MPa, os concretos contendo metacaulim e a sílica ativa apresentaram maiores resistências à compressão, resultando na redução de tal índice. Por fim, no parâmetro de liberação de temperatura para cada $100 \mathrm{~kg}$ de ligante, os resultados do concreto contendo CP V - ARI não diferenciaram significativamente dos contendo metacaulim e sílica ativa.

Os concretos contendo CP III - RS apresentaram as menores elevações de temperatura e liberação de calor por MPa, sendo uma alternativa eficiente na diminuição da elevação da temperatura dos concretos, interessante para prevenir patologias de origem térmica. Porém, encontra-se na literatura relatos de liberação de calor do CP III - RS semelhante à do CP V - ARI, evidenciando a necessidade da realização de estudos preliminares antes da utilização do ligante na produção de concretos.

O regime de cura não apresentou influência significativa na resistência à compressão dos concretos. A cura em temperaturas elevadas beneficia a resistência à compressão nas primeiras idades, pelo aumento da velocidade de hidratação dos compostos, principalmente na presença de adições minerais reativas. Entretanto, tal aceleração causa um prejuízo na formação da microestrutura do concreto, comprometendo a resistência do material à longo prazo. Assim, em idades superiores, espera-se que a resistência à compressão dos concretos curados em temperatura ambiente superem às dos curados em regime adiabático, conforme verificado no presente estudo.

Para os resultados do ensaio de termogravimetria, verificou-se que as amostras produzidas com metacaulim foram comandadas pelo fenômeno da reação pozolânica, já as amostras produzidas com o ligante CP $\mathrm{V}$ - ARI + sílica ativa demonstraram serem geridas principalmente pelo fenômeno de produção de pontos de nucleação. Isso explica o motivo de maiores resistências para mesmas relações água/ligante, no ensaio de resistências à compressão, para os concretos produzidos com o ligante CP V - ARI + metacaulim.

Por fim, verificou-se que as maiores resistências à compressão foram obtidas pela combinação de CP $\mathrm{V}$ - ARI + sílica ativa; porém, as relações água/ligante desta combinação são menores do que as relações água/ligante do CP V - ARI + metacaulim. Para mesmas relações água/ligante, a combinação CP V - ARI + metacaulim apresentou maior resistência que as demais, sendo provavelmente associado ao fato desta adição mineral apresentar elevada atividade pozolânica. Já na combinação CP V - ARI + sílica ativa, a adição mineral parece ter contribuído de forma muito mais pronunciada pela formação de pontos de nucleação, apresentando pouca influência de atividade pozolânica, já que observou-se um baixo consumo de hidróxido de cálcio.

\section{BIBLIOGRAFIA}

[1] DE MATOS, P.R., JUNCKES, R., PRUDÊNCIO JR., L.R. "Influência do uso de cinza volante na elevação adiabática de temperatura e resistência à compressão de concretos”, Revista Matéria, v. 24, e-12359, 2019.

[2] TAYLOR, H.F.W. Cement chemistry. 2nd ed., London: Thomas Telford, 1997.

[3] MEHTA, K.P., MONTEIRO, M.J.P. Concreto: microestrutura, propriedades e materiais. $2^{\circ}$ edição. Edição: Nicole Pagan Rasparyk. IBRACON, São Paulo-SP, 2014.

[4] ALBUQUERQUE, C.A. Estudo das propriedades de concreto massa com adição de partículas de borracha de pneu. Tese de D.Sc. Universidade Federal do Rio Grande do Sul. Programa de Pós-Graduação em Engenharia civil. Porto Alegre-RS, 2009.

[5] CARLES-GIBERGUES, A. HORNAIN, H. Durabilidade do concreto: bases cientificas para a formulação de concretos duráveis de acordo o ambiente. Ibracon, São Paulo, 2014.

[6] LIDUÁRIO, S.A. Contribuição ao estudo das propriedades térmicas do concreto convencional na presença das adições minerais. Dissertação de M.Sc. Programa de Pós-Graduação em Geotecnia, Estruturas e construção Civil. Universidade Federal de Goiás. Goiânia-GO, 2006.

[7] NEVILLE, A.M. Propriedades do Concreto. $2^{\mathrm{a}}$ Ed. São Paulo: Editora Pini Ltda, Tradução Salvador Eugênio Giammusso, 1997.

[8] EQUIPE DE FURNAS, Laboratório de Concreto. Concretos massa, estrutural, projetado e compactado com rolo - Ensaios e propriedades. Editor Walton Pacelli de Andrade, Editora. PINI, São Paulo, 1997. 
[9] LIDUÁRIO, A.S., FARIAS, L.A., ANDRADE, M.A.S. et al.,Estudo da influência de adições pozolânicas e minerais no concreto. Furnas, (2008).

[10] KADRI E., KENAI, S., EZZIANE, K., et al., "Influence of metakaolin and silica fume on the heat of hydration and compressive strength development of mortar". Applied Clay Science, v.53, pp. 704-708, 2011.

[11] HAN, F., HE, X., ZHANG, Z., et al.,"Hydration heat of slag or fly ash in the composite binder at different temperatures". Thermochimica Acta. Pp. 202-210, 2017.

[12] JUNCKES, R. Influência da adição de cinza volante na elevação de temperatura de concretos aplicados em blocos de fundação. Dissertação M.Sc. Universidade Federal de Santa Catarina, Programa de PósGraduação em Engenharia civil, Florianópolis-SC, 2015.

[13] COUTO, D., HELENE, P., ALMEIDA, L.C. "Monitoramento de temperatura em sapata de fundação de grande porte: estudo de caso "Parque da Cidade" - SP". ISSN 1983-4195. Revista IBRACON de Estruturas e Materiais. v. 9, n. 6, pp. 953-968. Dez. 2016.

[14] ASSOCIAÇÃO BRASILEIRA DE NORMAS TÉCNICAS NBR NM 67: Concreto - Determinação da consistência pelo abatimento do tronco de cone. Rio de Janeiro, 1998.

[15] GAMBALE, E.A., ANDRADE, M.A.A., BITTENCOURT, R.M., et al., Avaliação de resultados do ensaio de elevação adiabática do concreto massa com base em um novo calorímetro. IBRACON, $46^{\circ}$ Congresso Brasileiro de Concreto, Florianopolis, 2004.

[16] ASSOCIAÇÃO BRASILEIRA DE NORMAS TÉCNICAS NBR 5739: Concreto - Ensaios de compressão de corpos de prova cilíndricos. Rio de Janeiro, 2018.

[17] ASSOCIAÇÃO BRASILEIRA DE NORMAS TÉCNICAS NBR 5738: Concreto - Procedimento para moldagem e cura de corpos de prova. Rio de Janeiro, 2015.

[18] RAMLOCHAN, T., THOMAS, M.D.A., HOOTON, R.D. "The effects of pozzolans and slag on the expansion of mortars cured at elevated temperature part ii: microstructural and michochemical investigations". Cement and Concrete Research, pp. 1341-1356, 2004.

[19] DAL MOLIN, D.C.C. "Adições Minerais". In: ISAIA, G.C. (Ed) Concreto: Ciência e Tecnologia. Editora Ibracon, 1 $1^{a}$ Edição, São Paulo, v. 1, pp. 261-310, 2011

[20] NARMLUK, M., NAWA, T. "Effect of fly ash on the kinetics of Portland cement hydration at different curing temperatures". Cement and Concrete Research, v. 41, pp. 579-589, 2011.

[21] DESCHNER, F., LOTHENBACH, B., WINNEFELD, F., et al., "Effect of temperature on the hydration of Portland cement blended with siliceous fly ash". Cement and Concrete Research, v. 52, pp. 169-181, 2013.

[22] KUMAR, M., SINGH, S.K., SINGH, N.P. "Heat evolution during the hydration of Portland cement in the presence of fly ash, calcium hydroxide and super plasticizer". Thermochimica Acta, v. 548, pp. 27-32, 2012.

[23] HAN F., LIU R., WANG D., et al.,"Characteristics of the hydration heat evolution of composite binder at different hydrating temperature". Thermochimica Acta. 586, pp. 52-57, 2014.

[24] ASAGA, K., ISHIZAKI, M., TAKAHAGH, S., et al., "Effect of curing temperature on the hydration of portland cement compounds". In: International Conference On Computer Communication, 9, 1992.

[25] LOTHENBACH, B., SCRIVENER, K., HOOTON, R.D. "Supplementary cementitious materials". Cement and Concrete Research. v. 41, n. 12, p. 1244-1256, 2011.

[26] BERODIER, E., SCRIVENER, K. "Understanding the filler effect on the nucleation and growth of C-SH. J". American Ceramic Society. 97, pp. 3764-3773, 2014.

[27] SCRIVENER, K.L., JUILLAND, P., MONTEIRO, P.J.M. "Advances in understanding hydration of Portland cement". Cement and Concrete Research. Res. 78, pp. 38-56, 2015.

[28] DIAS, E.G., GAMBALE, E.A., FONTOURA, J.T.F., et al., "Estudo da influência do cimento Portland de alto-forno e cimento Portland comum com adição de escória de alto-forno moída nas propriedades do concreto". In: 32 Reunião do Instituto Brasileiro do Concreto - IBRACON, Fortaleza, v.2, 1990.

[29] ESCALANTE, J. J., GÓMEZ, L.Y., JOHAL, K.K. et al., "Reactivity of blast-furnace slag in Portland cement blends hydrated under different conditions". Cement and Concrete Research. Pp. 1403-1409, 2001.

[30] TAM, C.T., LOO, Y.H., CHOONG, K.F., "Adiabatic temperature rise in concrete with and without GGBFS”. In: Proceedings - ACI International Conference, Editor V.M. Malhotra, Singapore, SP - 149, 1994. 
[31] RAMACHANDRAN, V.S; Concrete admixtures handbook-Properties, science, and technology. $2^{\mathrm{a}}$ edição, ISBN 0-8155-1373-9, 1995.

[32] MALHOTRA, V.M., MEHTA, P.K, “Pozzolanic and cementitious materials". Advanced Concrete Techonology Program. CANMET, Ottawa, Ontario, Canada, v. 1, 1996.

[33] KADRI, E.H., DURVAL, R. "Hydration heat kinetics of concrete with silica fume". Construction and Building Materials. V. 23, pp. 3388-3392, 2009.

[34] NILI, M., SALEHI, A.M. "Acessing the effectiveness of pozzolans in massive high-strenght concrete". Construction and Building Materials. Pp. 2108-2116, 2010.

[35] BARATA, S.M., DAL MOLIN, C.C.D. “Avaliação preliminar do resíduo caulinitico das industrias de beneficiamento de caulim como matéria prima na produção de uma metacaulinita altamente reativa". Ambiente Construído, v. 2, pp. 69-78, 2002.

[36] LANGAN, W.B., WENG, K., WARD, A.M. "Effect of silica fume and fly ash on heat of hydration of Portland cement". Cement and Concrete Research, v. 32, pp. 1045-1051, 2002.

\section{ORCID}

André Valmir Saugo Ribeiro

Luiz Roberto Prudêncio Jr.

Paulo Ricardo de Matos

Alex Taira https://orcid.org/0000-0003-1156-0938

https://orcid.org/0000-0002-7594-7077

https://orcid.org/0000-0002-3695-1356

https://orcid.org/0000-0002-1386-1112 